\title{
Diplóides (AA) de bananeira submetidos ao estresse salino
}

Eline Waked Ferreira Gomes ${ }^{(1)}$, Lilia Willadino(1), Luiza Suely Semen Martins ${ }^{(1)}$, Sebastião de Oliveira e Silva(2), Terezinha Rangel Camara ${ }^{(3)}$ e Isabelle Maria Jaqueline Meunier ${ }^{(4)}$

(1)Universidade Federal Rural de Pernambuco (UFRPE), Dep. de Biologia, Rua D. Manoel de Medeiros s/no, Dois Irmãos, CEP 52171-900 Recife, PE. E-mail: lilia@truenet.com.br, luizasemen@hotmail.com (2)Embrapa Mandioca e Fruticultura, Caixa Postal 007, CEP 44380-000 Cruz das Almas, BA. E-mail: ssilva@cnpmf.embrapa.br (3)UFRPE, Dep. de Química. E-mail: tcamara@novaera.com.br (4)UFRPE, Dep. de Ciência Florestal. E-mail: meunier@hotlink.com.br

Resumo - No Nordeste do Brasil a salinização dos solos é um dos fatores limitantes na produção de bananeira. Estudos quanto à tolerância à salinidade em diplóides de bananeira são importantes para programas de melhoramento genético. Esse trabalho objetivou avaliar os efeitos da salinidade utilizando variáveis químicas e de crescimento, e quantificar, mediante padrões isoenzimáticos, a diversidade genética entre seis genótipos diplóides (AA), associando-os à tolerância à salinidade. As plantas foram tratadas durante 21 dias com 0, 50 e $100 \mathrm{mM}$ de $\mathrm{NaCl}$, num delineamento experimental inteiramente casualizado. Os diplóides Lidi e Calcuttá apresentaram maiores reduções na área foliar e fortes sintomas de toxidez associados aos maiores acúmulos de $\mathrm{Na}^{+} \mathrm{e} \mathrm{Cl}^{-}$no limbo. Os genótipos Borneo e S№/2 apresentaram discretos sintomas de toxidez e, como o genótipo M-53, demonstraram habilidade de evitar a translocação excessiva de $\mathrm{Na}^{+} \mathrm{e} \mathrm{Cl}$ para as folhas preservando o aparelho fotossintético. Nos diplóides S№/2 e M-53 foi detectada uma banda específica (Po-6) do sistema peroxidase, sob condições de estresse salino. Associando as características isoenzimáticas com as de crescimento, sintomatologia, análise mineral e grau de similaridade genética entre os genótipos, os dendrogramas construídos separam os genótipos mais tolerantes (S№/2 e M-53) dos mais sensíveis (Lidi e Calcuttá).

Termos para indexação: Musa, salinidade, isoenzimas.

\section{Banana diploids (AA) submitted to salt stress}

Abstract - In the Northeast Region of Brazil, salinization in soils is one of the limiting factors for banana production. Studies regarding tolerance and salt sensitivity in banana diploids are important for genetic breeding programs. This work aimed to evaluate salt stress effects measuring growth and chemicals parameters and to quantify the genetic diversity among six diploids (AA) genotypes using isozymic standards relating to salt tolerance. The plants were treated during 21 days under 0,50 and $100 \mathrm{mM}$ of $\mathrm{NaCl}$ in a completely randomized design. The diploids Lidi and Calcuttá presented the greatest leaf area reduction and severe toxicity associated to greater $\mathrm{Na}^{+}$ and $\mathrm{Cl}^{-}$accumulation in leaf blades. The genotypes Borneo and S№/2 presented discrete symptoms of toxicity and like M-53 genotype, demonstrated the capacity of avoiding excessive translocation of $\mathrm{Na}^{+}$and $\mathrm{Cl}^{-}$to the leaves preserving the photosynthetic apparatus. Only the diploid S№/2 and M-53 showed a specific peroxidase band (Po-6), under salt stress. The relationship between the isoenzymatic and the growth and mineral analysis of vegetal tissue created dendrograms separating the most tolerant genotypes (SNN/2 and M-53) from the most sensitive ones (Lidi and Calcuttá).

Index terms: Musa, salinity, isoenzymes.

\section{Introdução}

A bananeira é cultivada em todos os estados brasileiros. Sua importância está associada tanto a fatores sociais como econômicos, já que seu consumo é grande e o seu cultivo contribui para a fixação do homem no campo e para geração de divisas no país (Rosa Júnior, 2000). A cultura é muito explorada nos perímetros irrigados do Nordeste. Essas áreas, entretanto, apresentam tendências no acúmulo de sais, pois, além das condições ambientais que favorecem a evapotranspiração, a água usada na irrigação não é de boa qualidade, sua aplicação, muitas vezes, é feita inadequadamente, além do sistema de drenagem ser, freqüentemente, deficiente (Rosa Júnior, 2000)

Os efeitos imediatos da salinidade sobre as plantas são: seca fisiológica provocada pela redução do potencial osmótico da solução do solo; desequilíbrio nutricional por causa da elevada concentração iônica e da inibição na absorção de outros cátions pelo sódio; e efeito tóxico 
dos íons $\mathrm{Na}^{+}$e $\mathrm{Cl}^{-}$(Munns et al., 2002). Além dos distúrbios fisiológicos, ocorrem variações nos padões dos sistemas isoenzimáticos, sobretudo das peroxidases, em plantas submetidas ao estresse salino. A expressão de bandas específicas de peroxidase em genótipos tolerantes à salinidade foi constatada por Sreenivasulu et al. (1999) em Setaria italica, e por Ulisses et al. (2002) em somaclones de bananeira.

A salinização dos solos é, sem dúvida, um dos fatores limitantes da produção (Santos \& Gheyi, 1994), e a utilização de cultivares de bananeira tolerantes a solos salinos desponta como uma solução viável para esse problema, pois as práticas de recuperação de solos salinizados são geralmente dispendiosas e demoradas.

O objetivo do melhoramento de bananeira com germoplasma AA é concentrar, em um mesmo genótipo, um bom número de pencas, frutos compridos, cachos bem formados, resistência a pragas e doenças, além de tolerância a estresses, incluindo-se o salino. Esses caracteres seriam, posteriormente, transferidos aos tetraplóides. Assim, a identificação de genótipos AA tolerantes à salinidade é muito importante para que possam ser utilizados em cruzamentos que resultem na obtenção de variedades com características que permitam a adaptação a solos salinos (Silva et al., 1999). Dados de tolerância e sensibilidade de diplóides de bananeira à salinidade ainda não são encontrados na literatura.

O objetivo deste trabalho foi avaliar os efeitos da salinidade utilizando variáveis de crescimento, químicas e moleculares e quantificar, mediante padrõe isoenzimáticos, a diversidade genética entre seis genótipos diplóides (AA) de bananeira, associando-os com a tolerância à salinidade.

\section{Material e Métodos}

O experimento foi realizado em casa de vegetação da Universidade Federal Rural de Pernambuco, PE Foram avaliados os diplóides (AA): Calcuttá, Borneo, Lidi, S№/2, Microcarpa e M-53, introduzidos pela Embrapa Mandioca e Fruticultura, em Cruz das Almas, BA (Tabela 1).

Mudas provenientes de cultura de tecidos, 30 dias após a aclimatação, foram plantadas em sacos de polietileno preto $(55 \mathrm{~cm}$ de altura por $33 \mathrm{~cm}$ de diâmetro) contendo $10 \mathrm{~kg}$ de areia lavada coberta por uma camada de $3 \mathrm{~cm}$ de cascalho fino, a fim de reduzir a evaporação e favorecer o controle da salinidade no substrato. Utilizou-se irrigação por gotejamento
(0,6 L/planta/dia). A condutividade elétrica da solução nutritiva dos três tratamentos foi mantida a, aproximadamente, 1,7, 6,8 e 11,3 dS m${ }^{-1}$, correspondendo às concentrações de 0,50 e $100 \mathrm{mM}$ de $\mathrm{NaCl}$, caracterizando três níveis de salinidade. Todos os tratamentos continham $742,86 \mathrm{mg} \mathrm{L}^{-1}$ de fertilizante solúvel com a seguinte composição: $3 \%$ de $\mathrm{N}, 11 \%$ de $\mathrm{P}_{2} \mathrm{O}_{5}, 38 \%$ de $\mathrm{K}_{2} \mathrm{O}, 4 \%$ de $\mathrm{MgO}, 11 \%$ de $\mathrm{S}$ e micronutrientes. O Ca e o $\mathrm{N}$ foram fornecidos na forma de nitrato de cálcio na dose de $840 \mathrm{mg} \mathrm{L}^{-1}$ do produto composto de $15,5 \%$ de $\mathrm{N}$ e $19 \%$ de Ca. Utilizou-se o delineamento experimental inteiramente casualizado com quatro repetições.

Por ocasião da coleta do experimento, 21 dias a partir da diferenciação dos tratamentos, a área foliar foi estimada multiplicando-se o produto do comprimento e largura da folha por 0,7 (modificado de Moreira, 1987). Foram coletados, separadamente, o limbo foliar, o pseudocaule e as raízes com o rizoma (raízes+rizoma). Nas análises dos elementos minerais, a matéria seca das diferentes partes da planta foi triturada em moinho de facas e submetida à digestão nitroperclórica. $\mathrm{O}$ extrato vegetal foi dissolvido e diluído em água deionizada para determinação dos teores de $\mathrm{Na}^{+}, \mathrm{K}^{+}$e $\mathrm{Ca}^{2+}$. Os teores de $\mathrm{Na}^{+} \mathrm{e} \mathrm{K}^{+}$foram determinados por meio de fotometria de chama, os de $\mathrm{Ca}^{2+}$ por espectrofotometria de absorção atômica e os de $\mathrm{Cl}^{-}$por titulometria do nitrato de prata (Malavolta et al., 1997). Os dados obtidos foram submetidos à análise de variância e as médias comparadas pelo teste de Tukey a 5\% de probabilidade.

$\mathrm{Na}$ realização das análises isoenzimáticas, foram coletados $350 \mathrm{mg}$ de matéria fresca da terceira folha de cada planta do tratamento controle $(0 \mathrm{mM}$ de $\mathrm{NaCl})$ e do tratamento com $100 \mathrm{mM}$ de $\mathrm{NaCl}$. A amostra vegetal foi triturada em almofariz, mantido em banho de gelo, com 1,0 mL de tampão Scandalios, $300 \mathrm{mg}$ de sacarose e $300 \mathrm{mg}$ de polivinilpirrolidona (PVP).

Tabela 1. Genótipos diplóides (AA), provenientes do Banco Ativo de Germoplasma (BAG) de bananeira da Embrapa Mandioca e Fruticultura, país de origem e características.

\begin{tabular}{llc}
\hline Genótipo & Origem & Características $^{(1)}$ \\
\hline Calcuttá & Jamaica & DS S \\
Borneo & Jamaica & DS S \\
Lidi & Honduras & DS P \\
SNo/2 & Nova Guiné & DS P \\
Microcarpa & Tailândia & DS P \\
M-53 & Jamaica & DMP \\
\hline
\end{tabular}

(1)DS: diplóide simples; DM: diplóide melhorado; S: produz semente; P: partenocárpico 
Os homogeneizados foram centrifugados a $14.000 \mathrm{rpm}$ durante 10 minutos, a $4^{\circ} \mathrm{C}$. Do sobrenadante foram, imediatamente, retirados $10 \mu \mathrm{L}$ e aplicados nos poços dos géis de poliacrilamida. Na análise eletroforética foi empregado o sistema de eletroforese horizontal (Alfenas, 1998), sob refrigeração, à temperatura de $4^{\circ} \mathrm{C}$ e ao potencial elétrico de $9,0 \mathrm{~V} \mathrm{~cm}^{-1}$. Após a corrida eletroforética, os géis foram revelados e corados em soluções apropriadas (Alfenas, 1998), para os seguintes sistemas isoenzimáticos: álcool desidrogenase (ADH), esterase (EST), malato desidrogenase (MDH), peroxidase (PO), glutamato oxaloacetato transaminase (GOT) e fosfatase ácida (ACP). Os sistemas isoenzimáticos foram selecionados em função de apresentarem atividades em trabalhos realizados com bananeira (Bhat et al., 1992; Gomes et al., 2002; Ulisses et al., 2002). O polimorfismo foi analisado segundo a presença ou ausência de bandas e também segundo a intensidade de bandas.

Mediante a interpretação dos zimogramas, os dados foram tabulados conforme a presença (1) ou ausência (0) de bandas nos géis, para serem usados no estudo de diversidade genética. As similaridades genéticas entre os genótipos foram estimadas usando-se o coeficiente de Dice (equivalente ao Nei \& Li, 1979), no programa NTSYS-pc (Numerical Taxonomy and Multivariate Analysis System, versão 1.70, Exeter software, NY, USA). O dendrograma foi construído no programa NTSYS-pc, usando a opção UPGMA (Unweighted PairGroup Method Arithmetic Average).

\section{Resultados e Discussão}

Nos genótipos Lidi e Calcuttá, o elevado teor de $\mathrm{Na}^{+}$ e $\mathrm{Cl}^{-}$no limbo foliar coincidiu com uma significativa redução de área foliar a partir dos $50 \mathrm{mM}$ de $\mathrm{NaCl}$ (Tabela 2). Os efeitos deletérios da salinidade sobre a área foliar também foram relatados em bananeira cultivada em solo salinizado artificialmente (Araújo Filho et al., 1995) ou irrigada com água salina (Gomes et al., 2002).
A salinidade inibe o crescimento foliar por causa da redução na taxa de assimilação líquida de $\mathrm{CO}_{2}$, provocada pelo fechamento dos estômatos em resposta ao baixo potencial da água do solo (Binzel et al., 1985), além da inibição da expansão celular provocada pelo sal (Orcutt \& Nilsen, 2000).

Os genótipos Lidi e Calcuttá apresentaram os maiores teores de $\mathrm{Na}^{+}$no limbo foliar, com incrementos de aproximadamente $254,7 \%$ (50 mM) e 638,1\% (100 mM) em relação à testemunha (Tabela 3 ). Foram observados sintomas de toxidez do $\mathrm{NaCl}$ em ambos os genótipos, caracterizados como pequenas manchas ao longo do limbo foliar inicialmente nas folhas velhas, evoluindo para um amarelecimento, queima das bordas e do ápice foliar.

Resultados similares já haviam sido constatados em relação ao genótipo Calcuttá (Gomes et al., 2002). Os genótipos Borneo, S№/2 e M-53 não apresentaram acúmulo significativo de $\mathrm{Na}^{+}$no limbo foliar (Tabela 3), reduzindo os efeitos deletérios que seriam causados em processos como a fotossíntese, metabolismo do N, respiração, entre outros processos vitais. Não foram observadas diferenças entre os genótipos em relação aos teores de $\mathrm{Na}^{+}$nas raízes e rizoma, entretanto, em todos os genótipos houve acúmulo de $\mathrm{Na}^{+}$no material submetido a $100 \mathrm{mM}$ de $\mathrm{NaCl}$ (Tabela 3). O excesso de $\mathrm{Na}^{+}$ na solução do solo provoca acúmulo passivo desse cátion na raiz (Botella et al., 1997). Esse órgão, entretanto, apresenta uma capacidade limitada como reservatório (Garcia-Sanchez et al., 2002). Aparentemente, o mecanismo de translocação do $\mathrm{Na}^{+}$para as folhas é regulado, separadamente, do mecanismo de absorção pela raiz. Distúrbios fisiológicos e bioquímicos em plantas sensíveis ocorrem pela falta de habilidade em regular a concentração de $\mathrm{Na}^{+}$em tecidos metabolicamente ativos como os das folhas (Boursier \& Läuchli, 1990).

$\mathrm{O}$ aumento do nível de $\mathrm{NaCl}$ na solução aumentou também a concentração de $\mathrm{Cl}^{-}$em todas as partes da planta, de todos os genótipos. Nos diplóides Lidi e Calcuttá o teor de $\mathrm{Cl}^{-}$no limbo foliar, no tratamento com $100 \mathrm{mM}$, superou os demais genótipos apresentando, em

Tabela 2. Área foliar $\left(\mathrm{cm}^{2}\right)$ de seis genótipos diplóides de bananeira submetidos a três níveis de $\mathrm{NaCl}^{(1)}$.

\begin{tabular}{ccccccc}
\hline$(\mathrm{mM})$ & \multicolumn{1}{c}{ SNo/2 } & \multicolumn{1}{c}{ Borneo } & \multicolumn{1}{c}{ Calcuttá } & Microcarpa & M 53 & Lidi \\
\hline 0 & $6.233,7 \mathrm{aA}$ & $5.029,3 \mathrm{aAB}$ & $6.280,2 \mathrm{aA}$ & $5.100,5 \mathrm{aAB}$ & $3.520,0 \mathrm{aB}$ & $5.013,5 \mathrm{aAB}$ \\
50 & $5.135,5 \mathrm{aA}$ & $4.020,1 \mathrm{aABC}$ & $4.404,4 \mathrm{bAB}$ & $3.800,9 \mathrm{aABC}$ & $2.303,8 \mathrm{aC}$ & $3.217,0 \mathrm{bBC}$ \\
100 & $2.924,8 \mathrm{bA}$ & $2.634,3 \mathrm{abAB}$ & $2.405,3 \mathrm{cA}$ & $2.507,8 \mathrm{abAB}$ & $1.377,1 \mathrm{abB}$ & $1.889,8 \mathrm{bAB}$ \\
\hline
\end{tabular}

(1)Médias seguidas pelas mesmas letras, minúsculas nas colunas e maiúsculas nas linhas, não diferem entre si pelo teste de Tukey a $5 \%$ de probabilidade. 
média, um incremento de 492,3\% em relação à testemunha. Esses resultados corroboram os de Ferreira et al. (2001) e Gomes et al. (2002). A sobrevivência de plantas glicófitas em ambientes salinos pode resultar de processos adaptativos envolvendo absorção, transporte e distribuição de íons nos vários órgãos da planta, bem como a sua compartimentalização celular (Munns et al., 2002). Os genótipos Calcuttá e Lidi não foram eficientes em evitar o acúmulo dos íons tóxicos $\left(\mathrm{Na}^{+} \mathrm{e} \mathrm{Cl}^{-}\right)$na parte aérea.

A acumulação de $\mathrm{Na}^{+}$no pseudocaule coincidiu com uma redução porcentual média de $35,8 \%$ no teor de $\mathrm{K}^{+}$ no tratamento com $100 \mathrm{mM} \mathrm{NaCl}$. No limbo foliar, o teor de $\mathrm{K}^{+}$caiu em $51,9 \%$ e $53,7 \%$ nos genótipos
Calcuttá e M-53, respectivamente. Nos demais genótipos registrou-se apenas uma tendência de queda da concentração desse cátion (Tabela 3). $\mathrm{O}$ aumento da concentração de $\mathrm{Na}^{+}$nos tecidos de espécies glicófitas geralmente está associado à diminuição na concentração de $\mathrm{K}^{+}$(Greenway \& Munns, 1980). Os genótipos Lidi e Calcuttá apresentaram elevados valores de relação $\mathrm{Na}^{+} / \mathrm{K}^{+}$no limbo foliar, superando os demais genótipos tanto no tratamento com $50 \mathrm{mM}(0,52)$ como no tratamento com $100 \mathrm{mM}$ de $\mathrm{NaCl}(1,24$ e 1,73 , respectivamente). A alta relação $\mathrm{Na}^{+} / \mathrm{K}^{+}$desses genótipos resultou mais do acúmulo de $\mathrm{Na}^{+}$do que da restrição à absorção ou translocação do $\mathrm{K}^{+}$. No que se refere ao controle do transporte do $\mathrm{Na}^{+}$, existem, conforme Munns et al. (2002),

Tabela 3. Teores de íons no limbo foliar, pseudocaule e raízes+rizoma, em seis genótipos diplóides de bananeira, em estádio inicial de desenvolvimento, aos 21 dias de tratamento com $\mathrm{NaCl}^{(1)}$.

\begin{tabular}{|c|c|c|c|c|c|c|c|c|c|}
\hline \multirow[t]{2}{*}{ Genótipos } & \multicolumn{9}{|c|}{$\mathrm{NaCl}(\mathrm{mM})$} \\
\hline & 0 & 50 & 100 & 0 & 50 & 100 & 0 & 50 & 100 \\
\hline & \multicolumn{3}{|c|}{----------Limbo foliar----------- } & \multicolumn{3}{|c|}{$\begin{array}{c}\mathrm{Na}^{+}\left(\mathrm{g} \mathrm{kg}^{-1}\right) \\
-1\end{array}$} & \multicolumn{3}{|c|}{--------Raízes+rizoma-------- } \\
\hline Lidi & $3,0 \mathrm{aC}$ & $11,8 \mathrm{aB}$ & $23,2 \mathrm{aA}$ & $1,9 \mathrm{aC}$ & $10,1 \mathrm{aB}$ & $18,4 \mathrm{aA}$ & $4,0 \mathrm{aB}$ & $6,2 \mathrm{aB}$ & $13,2 \mathrm{aA}$ \\
\hline Microcarpa & $3,8 \mathrm{aB}$ & 7,0aAB & $10,2 \mathrm{bA}$ & $1,6 \mathrm{aC}$ & $5,0 \mathrm{bB}$ & $10,7 \mathrm{bA}$ & $4,0 \mathrm{aB}$ & 7,5aAB & $10,0 \mathrm{aA}$ \\
\hline Calcuttá & $3,7 \mathrm{aC}$ & $11,7 \mathrm{aB}$ & $26,0 \mathrm{aA}$ & $1,6 \mathrm{aC}$ & $10,3 \mathrm{aB}$ & $18,6 \mathrm{aA}$ & $3,4 \mathrm{aB}$ & $8,7 \mathrm{aA}$ & $11,3 \mathrm{aA}$ \\
\hline Borneo & $3,5 \mathrm{aA}$ & $5,0 \mathrm{aA}$ & $7,8 \mathrm{bA}$ & $1,3 \mathrm{aC}$ & $8,1 \mathrm{abB}$ & $11,5 \mathrm{bA}$ & $4,3 \mathrm{aB}$ & $6,2 \mathrm{aB}$ & $11,3 \mathrm{aA}$ \\
\hline $\mathrm{SN}$ ㅇ/2 & $3,0 \mathrm{aA}$ & $5,0 \mathrm{aA}$ & $6,4 \mathrm{bA}$ & $1,6 \mathrm{aC}$ & $8,2 \mathrm{abB}$ & $12,5 \mathrm{bB}$ & $4,0 \mathrm{aB}$ & $8,8 \mathrm{aA}$ & $10,8 \mathrm{aA}$ \\
\hline \multirow[t]{2}{*}{ M-53 } & $3,4 \mathrm{aA}$ & $5,6 \mathrm{aA}$ & $7,8 \mathrm{bA}$ & $1,3 \mathrm{aC}$ & $8,4 \mathrm{abB}$ & $12,3 \mathrm{bA}$ & $3,4 \mathrm{aB}$ & $7,9 \mathrm{aA}$ & $11,5 \mathrm{aA}$ \\
\hline & \multicolumn{9}{|c|}{$\mathrm{Cl}\left(\mathrm{g} \mathrm{kg}^{-1}\right)$} \\
\hline Lidi & $10,6 \mathrm{aC}$ & $35,0 \mathrm{aB}$ & $51,5 \mathrm{aA}$ & $9,5 \mathrm{aB}$ & $36,6 \mathrm{aA}$ & $47,1 \mathrm{aA}$ & $12,4 \mathrm{aB}$ & $33,5 \mathrm{aA}$ & $36,6 \mathrm{aA}$ \\
\hline Microcarpa & $11,0 \mathrm{aB}$ & $31,6 \mathrm{aA}$ & $32,5 \mathrm{bA}$ & $7,4 \mathrm{aB}$ & $36,0 \mathrm{aA}$ & $41,9 \mathrm{aA}$ & $5,6 \mathrm{aB}$ & $29,1 \mathrm{aA}$ & 27,9aA \\
\hline Calcuttá & $8,0 \mathrm{aC}$ & $34,3 \mathrm{aB}$ & $55,9 \mathrm{aA}$ & $6,8 \mathrm{aB}$ & $36,3 \mathrm{aA}$ & $47,3 \mathrm{aA}$ & $3,9 \mathrm{aB}$ & $44,7 \mathrm{aA}$ & $45,9 \mathrm{aA}$ \\
\hline Borneo & $10,3 \mathrm{aB}$ & $22,9 \mathrm{aAB}$ & $29,2 \mathrm{bA}$ & $7,9 \mathrm{aB}$ & $34,8 \mathrm{aA}$ & $43,4 \mathrm{aA}$ & $9,9 \mathrm{aB}$ & $32,8 \mathrm{aA}$ & $32,9 \mathrm{aA}$ \\
\hline SN/2 & $6,7 \mathrm{aB}$ & $19,8 \mathrm{aAB}$ & $30,9 \mathrm{bA}$ & $6,5 \mathrm{aB}$ & $25,4 \mathrm{aAB}$ & $41,0 \mathrm{aA}$ & $4,4 \mathrm{aB}$ & $35,3 \mathrm{aA}$ & $43,4 \mathrm{aA}$ \\
\hline \multirow[t]{2}{*}{ M-53 } & $9,2 \mathrm{aB}$ & $21,0 \mathrm{aAB}$ & $24,8 \mathrm{bA}$ & $8,0 \mathrm{aB}$ & $24,6 \mathrm{aAB}$ & $32,9 \mathrm{aA}$ & $9,9 \mathrm{aB}$ & $41,6 \mathrm{aA}$ & $42,8 \mathrm{aA}$ \\
\hline & \multicolumn{9}{|c|}{$\mathrm{K}^{+}\left(\mathrm{g} \mathrm{kg}^{-1}\right)$} \\
\hline Lidi & $28,7 \mathrm{aA}$ & $22,5 \mathrm{aA}$ & $18,7 \mathrm{bA}$ & $87,3 \mathrm{abA}$ & 96,3abA & $54,4 \mathrm{aB}$ & $45,0 \mathrm{aA}$ & $45,0 \mathrm{aA}$ & $40,0 \mathrm{aA}$ \\
\hline Microcarpa & $31,2 \mathrm{aA}$ & $30,0 \mathrm{aA}$ & $22,5 \mathrm{abA}$ & 74,7abA & $67,0 \mathrm{cA}$ & $44,6 \mathrm{aB}$ & $41,2 \mathrm{aA}$ & $38,7 \mathrm{aA}$ & $37,5 \mathrm{aA}$ \\
\hline Calcuttá & $31,2 \mathrm{aA}$ & $22,5 \mathrm{aAB}$ & $15,0 \mathrm{bB}$ & $91,4 \mathrm{aA}$ & $105,5 \mathrm{aA}$ & $61,0 \mathrm{aB}$ & 46,3aA & $43,7 \mathrm{aA}$ & $40,0 \mathrm{aA}$ \\
\hline Borneo & $27,5 \mathrm{aA}$ & $25,0 \mathrm{aA}$ & $32,5 \mathrm{aA}$ & $75,9 \mathrm{abA}$ & $67,0 \mathrm{cA}$ & $50,8 \mathrm{aB}$ & $42,5 \mathrm{aA}$ & $42,0 \mathrm{aA}$ & $38,7 \mathrm{aA}$ \\
\hline SNo/2 & $28,7 \mathrm{aA}$ & $27,5 \mathrm{aA}$ & $26,2 \mathrm{abA}$ & $73,1 \mathrm{bA}$ & $79,1 \mathrm{bcA}$ & $48,7 \mathrm{aB}$ & 47,5aA & $38,7 \mathrm{aA}$ & 42,5aA \\
\hline \multirow[t]{2}{*}{ M-53 } & $35,0 \mathrm{aA}$ & $27,5 \mathrm{aA}$ & $16,2 \mathrm{bB}$ & $83,3 \mathrm{abA}$ & $75,1 \mathrm{cA}$ & $52,8 \mathrm{aB}$ & $46,2 \mathrm{aA}$ & $33,7 \mathrm{aB}$ & 31,2aB \\
\hline & \multicolumn{9}{|c|}{$\mathrm{Ca}^{2+}\left(\mathrm{g} \mathrm{kg}^{-1}\right)$} \\
\hline Lidi & $10,6 \mathrm{aA}$ & $8,2 \mathrm{aAB}$ & $5,6 \mathrm{aB}$ & $8,8 \mathrm{aA}$ & 7,6bA & $10,3 \mathrm{bA}$ & $6,6 \mathrm{bA}$ & $5,3 \mathrm{cA}$ & $4,6 \mathrm{bA}$ \\
\hline Microcarpa & $9,6 \mathrm{aA}$ & $8,6 \mathrm{aA}$ & 7,0aA & $8,9 \mathrm{aA}$ & $7,7 \mathrm{bA}$ & $7,4 \mathrm{bcA}$ & $10,7 \mathrm{aA}$ & $6,6 \mathrm{abB}$ & $5,3 \mathrm{abC}$ \\
\hline Calcuttá & $11,3 \mathrm{aA}$ & $8,7 \mathrm{aAB}$ & $6,5 \mathrm{aB}$ & $10,3 \mathrm{aB}$ & $12,3 \mathrm{aAB}$ & $15,7 \mathrm{aA}$ & $11,9 \mathrm{aA}$ & 7,7abB & 7,5aB \\
\hline Borneo & $12,4 \mathrm{aA}$ & $9,7 \mathrm{aAB}$ & $7,0 \mathrm{aB}$ & $10,4 \mathrm{aA}$ & 7,0bA & $6,7 \mathrm{bcA}$ & $10,2 \mathrm{aA}$ & 7,9aB & $5,7 \mathrm{abC}$ \\
\hline S№/2 & $9,3 \mathrm{aA}$ & $8,5 \mathrm{aA}$ & 7,0aA & $8,2 \mathrm{aA}$ & $6,6 \mathrm{bA}$ & $6,4 \mathrm{bcA}$ & 10,0aA & 7,6abB & $5,5 \mathrm{abC}$ \\
\hline M-53 & $10,5 \mathrm{aA}$ & $9,1 \mathrm{aA}$ & $6,8 \mathrm{aB}$ & $8,6 \mathrm{aA}$ & $6,0 \mathrm{bAB}$ & $4,9 \mathrm{cB}$ & $6,6 \mathrm{bA}$ & $5,2 \mathrm{cA}$ & $3,5 \mathrm{bB}$ \\
\hline
\end{tabular}

(1)Médias seguidas pelas mesmas letras, minúsculas nas colunas e maiúsculas nas linhas, não diferem entre si pelo teste de Tukey a de $5 \%$ de probabilidade. 
três pontos primordiais: absorção pelas raízes; carregamento do xilema; e remoção do $\mathrm{Na}^{+}$do xilema antes de atingir a parte aérea. Nesse último ponto, em muitas espécies, o $\mathrm{Na}^{+}$é retido, ou na parte superior do sistema radicular e na porção inferior da parte aérea, pelas células do estelo das raízes, ou na bainha vascular em caules e pecíolos (Munns et al., 2002). Neste trabalho, esse mecanismo parece ter sido ativado nos genótipos Borneo, M-53 e SNo/2, nos quais o acúmulo no teor de $\mathrm{Na}^{+}$registrou-se apenas no pseudocaule e nas raízes+rizoma.

Houve reduções nos teores de $\mathrm{Ca}^{2+}$ no limbo foliar e, principalmente, nas raízes+rizoma dos genótipos, com o
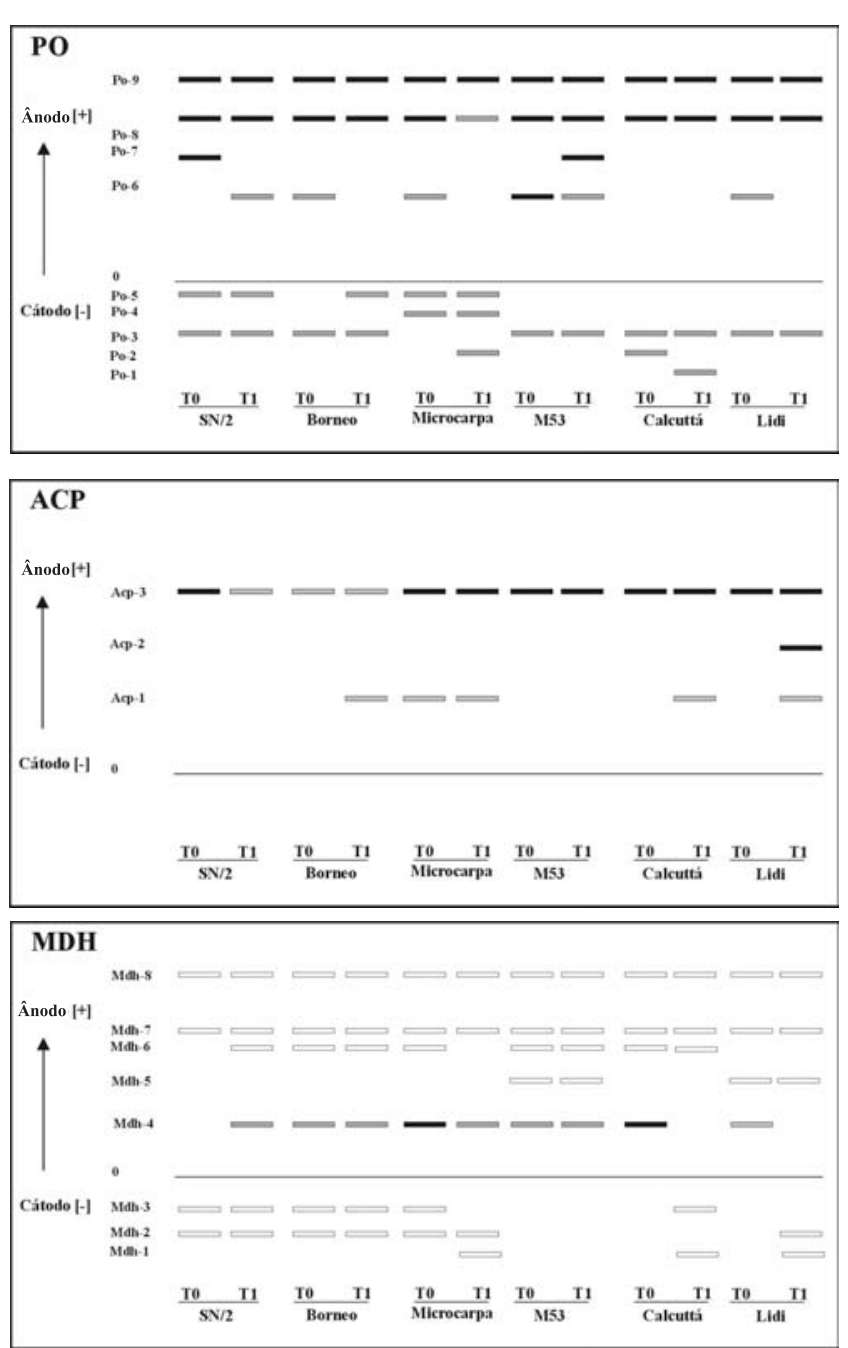

aumento da salinidade (Tabela 3). Numerosos estudos têm demonstrado que a salinidade induz à redução nos teores de $\mathrm{Ca}^{2+}$ em várias espécies, tanto no limbo foliar como nas raízes (Ferreira et al., 2001). A diminuição nos teores de $\mathrm{Ca}^{2+}$ coincidindo com o aumento da salinidade pode conduzir à maior sensibilidade da planta ao estresse salino, em razão da importância deste cátion na seletividade das membranas, nos processos de absorção, na compartimentação iônica, entre outros processos (Ferreira et al., 2001).

A partir de seis sistemas isoenzimáticos, foram obtidos 35 locos que apresentaram boa resolução (Figura 1). Os zimogramas obtidos revelaram que todos os siste-
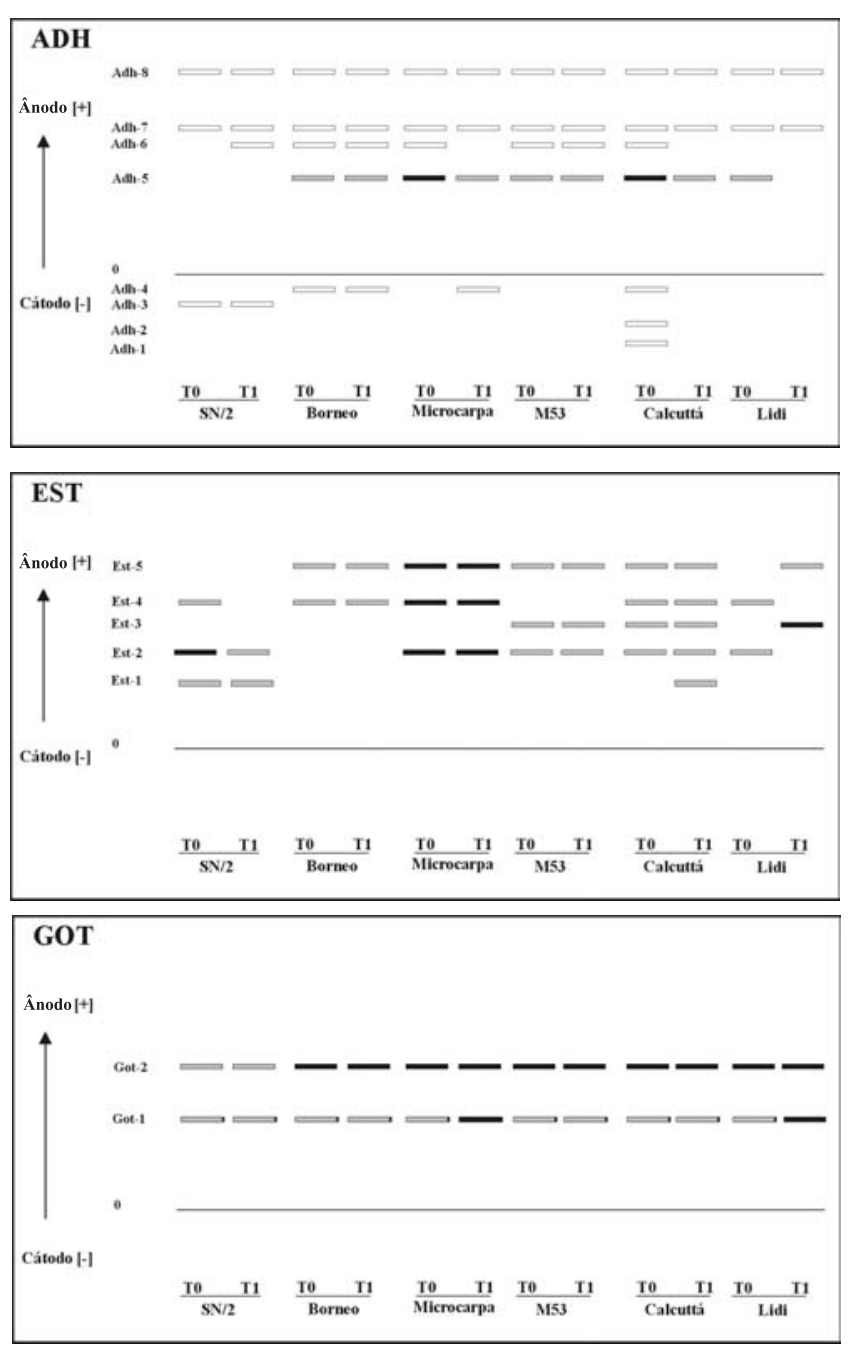

\begin{tabular}{|lll|}
\hline Banda forte & Banda fraca & Banda acromática \\
\hline
\end{tabular}

Figura 1.Zimogramas das variações isoenzimáticas de peroxidades (PO), álcool-desidrogenase (ADH), fosfatase ácida (ACP), esterase (EST), malato desidrogenase (MDH) e glutamato oxaloacetato transaminase (GOT) para os genótipos diplóides (AA) de bananeira, submetidos durante 21 dias à salinidade: T0, tratamento sem $\mathrm{NaCl}$ e T1, tratamento com $100 \mathrm{mM} \mathrm{de} \mathrm{NaCl}$. 
mas analisados apresentaram, em alguns acessos, variação na intensidade e no número de bandas em virtude da presença do $\mathrm{NaCl}$. Os diplóides avaliados produziram padrões de bandas mais complexos na maioria dos sistemas revelados por causa da expressão de dois alelos individuais.

Alguns autores têm registrado alterações quanto à presença e à ausência de proteínas em condições de estresse ambiental. Jain et al. (1993) constataram que a presença ou ausência de polipeptídeos de diferentes pesos moleculares ocorre em função do genótipo, do nível de salinidade aplicado e do tecido vegetal analisado. $\mathrm{O}$ estresse salino funciona como indutor de síntese de novas proteínas e essa síntese, provavelmente, está associada com o aumento da tolerância ao $\mathrm{NaCl}$ (Jain et al., 1993).

A peroxidase apresentou nove regiões de atividades distribuídas em quatro regiões de migração (Figura 1). Os locos catódicos se distribuíram em duas regiões de migração, ambas polimórficas. Sob estresse salino, a banda catódica do loco Po-2 foi revelada em Microcarpa e a Po-1, em Calcuttá. Das duas regiões anódicas, uma mostrou-se monomórfica (Po-9) e a outra, constituída pelos locos Po-6, Po-7 e Po-8, apresentou polimorfismo nos locos Po-6 e Po-7. No tratamento salino, dois dos três genótipos que apresentaram habilidade de evitar o acúmulo excessivo de $\mathrm{Na}^{+}$e $\mathrm{Cl}^{-}$, no limbo foliar, revelaram a banda do loco anódico Po-6. Esses dois genótipos, SNo/2 e M53, formaram um grupo à parte, conforme se discute mais adiante, considerando os dendrogramas construídos. $\mathrm{O}$ incremento da atividade de peroxidases é fundamental no controle da ação de espécies de oxigênio reativas responsáveis por danos oxidativos freqüentes em plantas submetidas ao estresse salino (Sreenivasulu et al., 1999).

A isoenzima $\mathrm{ADH}$ apresentou três regiões de migração (Figura 1). Na região I, correspondente aos locos Adh-6, Adh-7 e Adh-8, a banda Adh-6 foi ativada no genótipo SNo/2 no tratamento salino, sendo esse o único genótipo que apresentou incremento no número de bandas. Os locos Adh-1, Adh-2, Adh-3 e Adh-4, correspondentes à Região III, não foram ativados no genótipo Calcuttá, sob tratamento com $\mathrm{NaCl}$. Esse genótipo apresentou maior redução do número de bandas no tratamento salino.

Quanto ao sistema ACP, foram reveladas bandas em três locos (Figura 1). O loco Acp-3 mostrou-se ativo em todos os indivíduos, variando apenas quanto à intensidade das bandas. No tratamento com sal, o loco Acp-2 revelou banda apenas no genótipo Lidi e a banda do loco Acp-1 foi revelada nos genótipos Borneo, Microcarpa, Calcuttá e Lidi.

O sistema EST apresentou duas regiões de migração, uma formada por Est-3, Est-4 e Est-5, e outra, por Est-1 e Est-2 (Figura 1). Os genótipos Borneo, Microcarpa e M-53 apresentaram o mesmo padrão tanto na ausência quanto na presença do $\mathrm{NaCl}$. Calcuttá e Lidi tiveram as bandas Est-1 e Est-5, respectivamente, reveladas no tratamento com sal. Observou-se maior intensidade das bandas Est-2 e Est-4 no genótipo Lidi quando tratado com $\mathrm{NaCl}$. Essa indução pelo $\mathrm{NaCl}$ pode ser decorrência da sensibilidade dessa enzima à interferência de fatores abióticos (Silva et al., 2000).

No sistema MDH foi possível constatar quatro regiões de migração (Figura 1). Apenas a região I, composta pelo loco Mdh-8, teve comportamento monomórfico. Na quarta região, composta pelos locos Mdh-1, Mdh-2 e Mdh-3, o loco Mdh-1 revelou bandas apenas nos genótipos Microcarpa, Calcuttá e Lidi quando submetidos ao estresse salino. O alto grau de polimorfismo observado nesse sistema isoenzimático confirma os resultados obtidos em bananeiras por Bhat et al. (1992).

Os padrões isoenzimáticos da GOT revelaram duas regiões de atividades, presentes em todos os indivíduos (Figura 1). Dos sistemas estudados, este foi o mais monomórfico.

Os dendrogramas construídos de acordo com os graus de similaridade genética nos tratamentos salino e não salino, separadamente, indicam a formação de dois grupos distintos em cada tratamento (Figura 2).

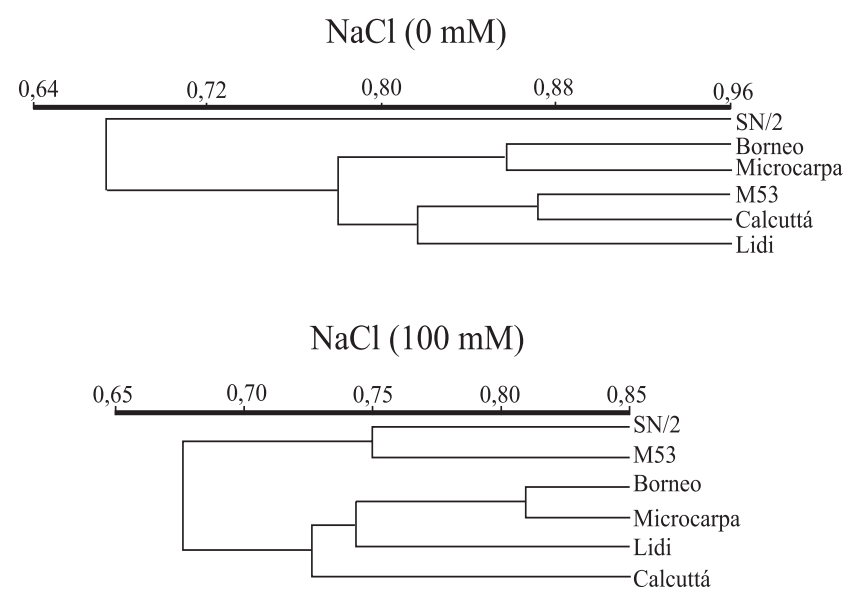

Figura 2. Análises de agrupamentos dos genótipos diplóides de bananeira, obtidas pelo programa NTSYS-pc usando a opção UPGMA (Unweighted Pair-Group Method Arithmetic Average), nos tratamentos T0 (0 mM de $\mathrm{NaCl})$ e T1 $(100 \mathrm{mM}$ de $\mathrm{NaCl})$. 
No dendrograma do tratamento salino um grupo é constituído pelos indivíduos SNo/2 e M-53 e outro formado pelos demais genótipos.

Após análise das características de crescimento, dos teores de nutrientes e dos dendrogramas, puderam ser separados os genótipos mais tolerantes (SNNo/2 e M-53) dos mais sensíveis (Lidi e Calcuttá).

\section{Conclusões}

1. A acumulação de $\mathrm{Na}^{+}$e $\mathrm{Cl}^{-}$no limbo foliar caracteriza a sensibilidade de genótipos de bananeira ao estresse salino, na fase inicial de crescimento.

2. A análise de similaridade e agrupamento genético de genótipos de bananeira sob condições de salinidade permite identificar materiais tolerantes (S№2 e M-53) a partir da associação com características de crescimento e com a expressão de bandas de peroxidase (Po-6).

\section{Referências}

ALFENAS, A.C. Eletroforese de proteínas afins: fundamentos aplicações em plantas e microrganismos. Viçosa: UFV, 1998. 57p. ARAÚJO FILHO, J.B. de; GHEYI, H.R.; AZEVEDO, N.C.; SANTOS, J.G.R. Tolerância da bananeira à salinidade na fase inicial de desenvolvimento. Pesquisa Agropecuária Brasileira, v.30 p.989-997, 1995.

BHAT, K.V.; BHAT, S.R.; CHANDEL, P.S. Survey of isozyme polymorfism for clonal in Musa. II: Peroxidase, superoxide desmutase, shikimate dehidrogenase and malate dehidrogenase. Journal of Horticultural Science, v.67, p.737-743, 1992.

BINZEL, M.L.; HASEGAWA, P.M.; HANDA, A.K.; BRESSAN, R.A. Adaptation of tobacco cells to NaCl. Plant Physiology, v.79, p.118-125, 1985.

BOTELLA, M.A.; PARDINES, J.; CERDÁ, A. Salinity induced potassium deficiency in maize plants. Journal of Plant Physiology, v.150, p.200-205, 1997.

BOURSIER, P.; LÄUCHLI, A. Growth response and mineral nutrient relations of salt-stressed Sorghum. Crop Science, v.30, p.12261233, 1990.

FERREIRA, R.G.; TÁVORA, FJ.A; HERNANDEZ, F.F.F. Distribuição da matéria seca e composição química das raízes, caule e folhas de goiabeira submetida a estresse salino. Pesquisa Agropecuária Brasileira, v.36, p.37-42, 2001
GARCIA-SANCHEZ, F.; JIFON, J.L.; CARVAJAL, M.; SYVERTSEN, J.P. Gás exchange, chlorophyll and nutrient contents in relation to $\mathrm{Na}^{+}$and $\mathrm{Cl}^{-}$in Sunburst mandarin grafted on different rootstocks. Plant Science, v.162, p.705-712, 2002.

GOMES, E.W.F.; WILLADINO, L.; MARTINS, L.S.S.; CAMARA, T.R.; SILVA, S.O. Genotypes of banana (Musa spp.) under saline stress: tolerance and sensitivity. InfoMusa, v.11, p.13-18, 2002.

GREENWAY, H.; MUNNS, R. Mechanism of tolerance in nonhalophytes. Annual Review of Plant Physiology, v.31, p.149-190, 1980

JAIN, S.; NAINAWATEE, H.S.; JAIN, R.K.; CHOWDHURY, J.B. Salt tolerance in Brassica juncea. Euphytica, v.65, p.107-112, 1993.

MALAVOLTA, E.; VITTI, G.C.; OLIVEIRA, S.A. Avaliação do estado nutricional das plantas: princípios e aplicações. Piracicaba: Potafos, 1997. 319p.

MOREIRA, R.S. Banana: teoria e prática de cultivo. Campinas: Fundação Cargill, 1987.335p.

MUNNS, R.; HUSAIN, S.; RIVELLI, A.R.; HARE, R.A. Progress in plant nutrition. Dordrecht: Kluwer Academic, 2002. 188p.

NEI, M.; LI, W.H. Matematical model for studying genetic variation in terms of restriction endonuclease. National Academy of Sciences of the United States of America, v.76, p.5269-5273, 1979. ORCUTT, D.M.; NILSEN, E.T. Physiology of plants under stress: soil and biotic factors. New York: J. Wiley, 2000. 683p.

ROSA JÚNIOR, C.D.R.M. Bananeira: cultivo sob condição irrigada. 2.ed. Recife: Sebrae, 2000. 51p.

SANTOS, J.G.R.; GHEYI, H.R. Efeito da salinidade da água na composição da folha da bananeira e nas características do solo. Pesquisa Agropecuária Brasileira, v.29, p.247-253, 1994.

SILVA, E.A.A. da; PINHO, E.V. de R.V.; VIEIRA, M.G.G.C.; CARVALHO, M.L.M. de; MACHADO, J.C. Alterações de isoenzimas em sementes de milho infectadas por fungos. Pesquisa Agropecuária Brasileira, v.35, p.1725-1732, 2000

SILVA, S de O e; CARVALHO PC.L de; SHEPHERD, K · ALVES, E.J.; OLIVEIRA, C.A.P. de; CARVALHO, J.A.B.S. Catálogo de germoplasma de bananeira (Musa spp.). Cruz das Almas: EmbrapaCNPMF, 1999. 152p. (Documentos, 90).

SREENIVASULU, N.; RAMANJULU, S.; RAMACHANDRAKINI, K.; PRAKASH, H.S.; SHEKAR-SHETTY, H.; SAVITHRI, H.S.; SUDHAKAR, C. Total peroxidase activity and peroxidase isoforms as modified by salt stress in two cultivars of fox-tail millett with differential salt tolerance. Plant Science, v.141, p.1-9, 1999. ULISSES, C.; CAMARA, T.R., WILLADINO, L.; ALBUQUERQUE, C.C. de; MARTINS, L.S.S.; FREITAS, N.S.A. Caracterização isoenzimática de clones de bananeira nanicão submetidos à salinidade. Revista Brasileira de Engenharia Agrícola e Ambiental, v.6, p.6-9, 2002.

Recebido em 25 de agosto de 2003 e aprovado em 26 de março de 2004 